\title{
ASSESSING THE IMPACT OF GAMIFICATION ON STUDENTS’ ENGAGEMENT AND MOTIVATION
}

\author{
J. RUIZALBA, A. Soares, J. Nato \\ University of West London (UNITED KINGDOM) \\ jruizdealba@gmail.com, belafsoares@gmail.com, jane.nato@uwl.ac.uk
}

Gamification is gaining momentum in Higher Education (HE) as scholars begin to enquire what they can learn from game experiences to improve students' engagement and motivation (Niman, 2014). Gamification does not mean using games, instead it refers to using game mechanisms or elements in contexts where games are not usually present (Kuo and Chang, 2015). Gamification is expected to contribute towards enjoyment and engagement (McGonigai, 2011). Engagement in academic success has been clearly established (e.g. Ibanez et al, 2014). In addition to this, motivation is also commonly accepted as the driving force that generates student engagement (Bomia et al., 1997). However, gamification cannot be seen as a quick fix to low students' engagement as it needs to be thoughtfully planned through before any implementation, otherwise it will just be a game without didactic purposes (Huotari and Hamari, 2012).

Following this, the gamified environment within the context of HE was defined and planned to facilitate the achievement of learning outcomes of a particular subject. Main aspects of the gamified environment included: (1) activities made available on a weekly basis with allocated points (such as multiple choice and Poll Everywhere questions, blog posts and self-made video uploads on relevant subject topics); (2) leader board publication on a weekly basis; (3) Predefined prizes for first three winners.

The present research aimed at investigating the impact of gamification on the levels of motivation and engagement of students regarding this particular subject. This exploratory study was conducted with a whole cohort of 150 students near completion of their BA Business Studies. In order to address the research objectives, a survey was conducted before and after the gamified experience, allowing an empirical analysis of data with the comparison of samples to identify main differences between those who participated.

Fitting within the university mission and innovation strategies, the results of this project could also then lead to a broader implementation of gamified activities in remaining subjects throughout university and particularly throughout the business degree considered.

\section{References:}

Bomia, L., Beluzo, L., Demeester, D., Elander, K., Johnson, M., \& Sheldon, B. (1997). The impact of teaching strategies on intrinsic motivation. Champaign, IL: ERIC Clearinghouse on Elementary and Early Childhood Education.

Huotari, K. \& Hamari, J (2012). Defining Gamification - A Service Marketing Perspective. Proceedings of the 16th International Academic MindTrek Conference, ACM Press, New York, USA, 17-22. 3.

Ibanez, M. B., Di-Serio, A., \& Delgado-Kloos, C. (2014). Gamification for Engaging Computer Science Students in Learning Activities: A Case Study. Learning Technologies, IEEE Transactions on, 7(3), pp.291-301.

Kuo, M. S., \& Chuang, T. Y. (2015). How gamification motivates visits and engagement for online academic dissemination-An empirical study. Computers in Human Behavior, 55, pp.16-27.

McGonigal, J. (2011). Reality is broken: Why games make us better and how they can change the world. New York: Penguin.

Niman, N. (2014), The Gamification of Higher Education: Developing a Game-Based Business Strategy in a Disrupted Marketplace, Palgrave Macmillan US.

Keywords: Gamification, Higher Education, Motivation, Engagement 